\title{
Factors affecting enterprise resource planning (ERP) systems adoption among higher education institutions in Egypt
}

\author{
Noorliza Karia, Mohamed Soliman* \\ Operations Department, School of Management, Universiti Sains Malaysia, USM, Malaysia, 11800 USM, Penang, Malaysia
}

\section{A RT ICLE INFO}

\section{Article history:}

Received 29 November 2016

Received in revised form

30 March 2017

Accepted 29 April 2017

\section{Keywords:}

ERP adoption

Intention to adopt ERP

TOE framework

Higher education

Egypt

\begin{abstract}
A B S T R A C T
The focus of enterprise resource planning (ERP) adoption among Higher Education Institutions (HEIs) has attracted the interest of many Information System (IS) researchers. As a result of its great business values, the adoption of ERP solution is increasingly growing within HEIs. However, very limited studies have focused their attention towards understanding the determinants of ERP adoption among HEIs, especially in Egypt. Furthermore, the adoption of ERP systems in Egypt is still in the beginning stage with no many adopters among HEIs. Therefore, this study aims to fill in the gap by investigating technological, organizational and environmental (TOE) framework among HEIs. Accordingly, the objective of this research paper is mainly trying to introduce a conceptualized research model that can be used to examine ERP adoption among HEIs. This article contributes to the development of theoretical framework of the ERP adoption to explain the competitive advantage within HEIs by using TOE framework. The current study will provide guidelines to ERP providers, the government, and HEIs in Egypt to accelerate ERP adoption.
\end{abstract}

(C) 2017 The Authors. Published by IASE. This is an open access article under the CC BY-NC-ND license (http://creativecommons.org/licenses/by-nc-nd/4.0/).

\section{Introduction}

ERP systems mainly indicated as integrated software applications that govern different departmental functions such as finance and human resource. As a result of the significant benefits of ERP systems, some universities have distributed an investment of more than five billion dollars in the ERP systems (Abugabah and Sanzogni, 2010).

This includes the processes of student recruitment, student admission, student records, financial aid for students as well as some of the universities' administrative and academic services (McCredie and Updegrove, 1999). If each business function has its own information system that is incompatible with the others, it will create a set of islands working in isolation without any kind of integration. When one integrating system such as ERP system is used for all business functions, then the database could be shared by everybody with the same accuracy (Al Kilani et al., 2012; Albadri, 2012).

Therefore, the adoption of the ERP system in universities is targeted to create progressive

\footnotetext{
* Corresponding Author.

Email Address: soliman2002s@yahoo.com (M. Soliman) https://doi.org/10.21833/ijaas.2017.05.025

2313-626X/C 2017 The Authors. Published by IASE.

This is an open access article under the CC BY-NC-ND license

(http://creativecommons.org/licenses/by-nc-nd/4.0/)
}

improvement levels of efficiency and performance so that colleges, departments, and schools have an improved capability for teaching and research at a low or at a practical cost (Watson and Schneider, 1999). In the same way, Egyptian HEIs can gain a competitive advantage from adopting ERP system because of higher quality educational services for lower costs and the usage of their resources most effectively (Soliman and Karia, 2015a). Despite the fact that the majority of universities have implemented an ERP system or are in the process of applying one (ALdayel et al., 2011; Ghuman and Chaudhary, 2012), there is a dearth of research investigating ERP system in the context of the environment of a university, in comparison to other environments.

Due to this emerging shift to ERP systems, a research question can be posed as to what are the factors that are significant predictors of ERP systems adoption among HEIs in Egypt. Based on results of recent literature analysis, however, there are not many ERP adoption studies (Al Kilani et al., 2012). Therefore, this study is important for several reasons. First, it contributes to existing literature by exploring the factors that may differentiate organizations that adopt ERP systems and organizations that do not adopt ERP systems. Second, understanding these factors may help ERP systems vendors understand important factors that 
may enhance demand for their products. HEIs in Egypt may also gain a better understanding of how such factors may enable or inhibit their ability to adopt new innovations.

The adoption of new IT innovation like ERP systems among HEIs requires great organizational, technological and business environmental commitments. Therefore, examining how these factors influence HEIs decision to adopt ERP is interesting, as it can help explains HEI's readiness, the influence of external pressures to adopt and to gain perceived benefits from using ERP (Pan and Jang, 2008). In order to understand the influence of the abovementioned factors, this study adopts Technology Organization and Environment (TOE) framework (Tornatzky et al., 1990). TOE posits that new IT innovation is determined by three important dimensions-technology, organization, and the environment.

Although TOE has been used to examine ERP adoption; it is not examined within higher Education context. Using TOE within this context might give different results as this context does not have the same ability to afford failures and budget overruns like the other environments when it comes to adopting new IT innovation. In this sense, a university has been regarded as a "unique" organization that is different from an organization in the corporate sector in the literature for several decades as they might be constrained by lack of resources (e.g. expertise, financial, technology) to carry out company-wide IT p rojects (Pollock and Cornford, 2004; Seo, 2013).

The motivation of this research is to discover the reasons for such few adopters of ERP systems among HEIs in Egypt (Soliman and Karia, 2015b). In other words, the researchers are interested in investigating the causes of the reluctance of HEIs in Egypt to adopt ERP system along with helping to provide guidelines to ERP providers, the government, and HEIs in Egypt to accelerate ERP adoption.

In conclusion, the study hopes to fill in the gap by answering the following research questions. 1) How can TOE framework be applied to ERP adoption among HEIs in Egypt? 2) To what extent TOE factors influence ERP adoption among HEIs in Egypt? 3) Which of TOE factors significantly influence ERP adoption among HEIs in Egypt?

\section{Literature review and the conceptual foundation}

\subsection{ERP adoption status in the context of Egypt}

Within the Egyptian context, there are not many studies being conducted to examine the determining factors of ERP adoption among HEIs. Previous studies discussed that the ERP systems in Egypt have merely placed a focus on two phases; preimplementation and implementation (El Sayed et al., 2013). For instance, some scholars investigate factors affect the success of ERP (Abdelghaffar and
Azim, 2010) and others identified factors contribute towards the relationship between business performance and ERP (Elragal and Al-Serafi, 2011) and the influence of cultural challenge on ERP adoption in Egypt, which differs from the other cultures from where the system of ERP is originated (El Sawah et al., 2008). However, recent surveys showed that the success rate of ERP implementations in Egypt is extremely lower than it is in western enterprises, and half of the ERP implementations in Egypt are considered as failures (Abdellatif, 2014).

Moreover, El-Seoud et al., (2014) clarified that the higher education sector in Egypt is enormous and included of public, private and foreign universities in addition to institutions of technical and skilled training. There are a lot of problems that occur in HIEs and ERP systems can emphatically contribute in changing and diminishing the impacts of these issues. Unfortunately, to date, the complete use of ERP has not been adopted by the foremost part of Higher Education sector in Egypt. To the best of our knowledge, this is the first empirical study that examines the determinants of ERP adoption using TOE theory within Higher education context in Egypt.

\subsection{Theoretical background}

Apparently, two theories are commonly used in innovation diffusion and adoption studies in organizations. They are the diffusion of innovation (DOI) theory (Rogers, 2003) and the TOE Framework (Tornatzky et al., 1990). However, other popular theories such as the technology acceptance model (TAM) (Davis, 1989; Davis, 1986), the theory of planned behaviour (TPB) (Ajzen, 1991), and the unified theory of acceptance and use of technology (UTAUT) (Venkatesh et al., 2003) are not considered in this research because they pertain to an individual's choice.

\subsubsection{Previous research on diffusion of innovation (DOI)}

DOI (Rogers, 2003) is a prominent adoption model used in Information Systems (IS) research (Dedrick and West, 2004; Ifinedo, 2011; MoraMonge et al., 2010; Shah Alam, 2009; Zhu et al., 2006). It suggests five aspects that illustrate the innovation adoption within an organization. They are: (1) relative advantage, mainly refers to the extent to which an innovation is better than the previous generation; (2) compatibility, explains the degree to which an innovation can be integrated into the present business processes, practices, and value systems; (3) complexity, describes how difficult it is to use the innovation; (4) observability, shows the extent to which the innovation is visible to others; and (5) trialability, confirms the ease of experimenting with the innovation. DOI is principally based on the technology characteristics and the users' perceptions of the innovation 
knowing that an organization is a more complex entity than an individual. Rogers (2003) suggested that innovation is a communication process using the various channels within the social system. Three factors influence the adoption of innovation in organizations. They are individual (leadership attitude toward change), internal organizational structure (centralization, complexity, interconnectedness, the number of employees, and organizational slack), and external characteristics (system openness) of the organization.

\subsubsection{Previous research on TOE framework}

A TOE framework is developed by (Tornatzky et al., 1990) to study the factors that may affect the adoption of technological innovation within the organization. Therefore, this framework is adopted to examine technology adoption from an organization point of view. It is proven to be relevant and consistent as a measurement scale for technology adoption studies in which it covers all contexts that need to be evaluated for technology adoption factors (Liaquat et al., 2002; Tornatzky et al., 1990). According to Tornatzky et al. (1990), this framework is divided into three main dimensions technology, organization, and the environment. Also, this theory has been used to examine the adoption of wide varieties of new IT innovation, such as RFID (Wang et al., 2010), knowledge management systems (Lee et al., 2009), ERP Cloud (Qian et al., 2016), IT decision-making processes (Bernroider and Schmöllerl, 2013), Web site e-commerce (Oliveira and Martins, 2010), Medical records system (MRS) adoption (Marques et al., 2011) and ERP systems (Bradford and Florin, 2003; Dwivedi et al., 2009; Haddara and Elragal, 2013; Lotfy, 2015; Pan and Jang, 2008; Ruivo et al., 2014).

\subsubsection{Previous research on combining DOI and TOE}

Many studies have provided a focus on combining more than one theoretical perspective to better understand the IT adoption of new technologies (Lyytinen and Damsgaard, 2011; Oliveira and Martins, 2011; Wu et al., 2013). In the same way, to better understand the organizational decisions related to the adoption of technological innovation, the context of the study should be comprehensive and the variables tailored to the specificit $y$ of the innovation (Chau and Tam, 1997). DOI and TOE have been used widely in IT adoption studies with some consistent empirical support. In many ways, the TOE perspectives overlap with the innovation characteristics identified by Rogers. Hence, the wellmeaning value of incorporating the TOE contexts to strongly support the DOI theory is well- recognized (Chau and Tam, 1997; Hsu et al., 2006; Wu et al., 2013).

Also; the context of technology is implicitly the same idea as that of Rogers (2003). Moreover, DOI's internal and external organizational characteristics include the same measures as TOE's organization context (Hsu et al., 2006). However, there are also main differences between the two theories. TOE does not identify the role of individual characteristics (e.g. top management support). Here, the DOI theory suggests the inclusion of top management support in the organization context. Similarly, DOI does not consider the impact of the environmental context. Due to DOI's shortcomings, the TOE framework helps to provide a more comprehensive perspective for understanding IT adoption by including the technology, organization, and environment contexts (Zhu et al., 2006). In conclusion, these theories thus meaningfully complement each other (Oliveira and Martins, 2011; Oliveira et al., 2014).

\section{Research model and hypotheses}

According to the above discussion, the proposed research framework of this study in Fig. 1 demonstrates the independent variables to be categorized into three contexts, which are technology, organization, and the environment. Therefore, one of the contributions of this research is to cover the gap in the literature by examining the impact of these factors of ERP adoption among HEIs in Egypt. This research, also, investigates the attributes that are related to the adoption of ERP and their effect on competitive advantage.

\subsection{Technological dimension}

Kuan and Chau (2001) and Zhu et al. (2003) demonstrated to the importance of internal technology resources for successful IS adoption. Zhu et al. (2004) highlighted that given the technologydriven nature of e-business, firms that make efficient use of Internet technologies and exhibit technology readiness are more suitable to create e-business value.

Moreover, sufficient financial resources help companies to acquire the necessary IT resources and achieve successful e-business implementation (Pan and Jang, 2008; Zhu and Kraemer, 2005; Zhu et al., 2004).

In this study, "Relative advantage" is defined as "the degree to which an innovation is perceived as being better than the idea it supersedes" (Rogers, 2003). Studies discovered that this varia ble to be positively identified with the adoption of IS innovations (Grandon and Pearson, 2004). At the point when an IS innovation is perceived to offer a relative advantage over the firm's current practice, it will probably be adopted (Lee, 2004). ERP systems provide many benefits to adopters regarding obliging business growth, enhancing business procedures and decreasing business working and regulatory costs (Markus and Tanis, 2000). Accordingly, in a highly competitive marketplace, these benefits make significant motivations for adopting these technologies. 


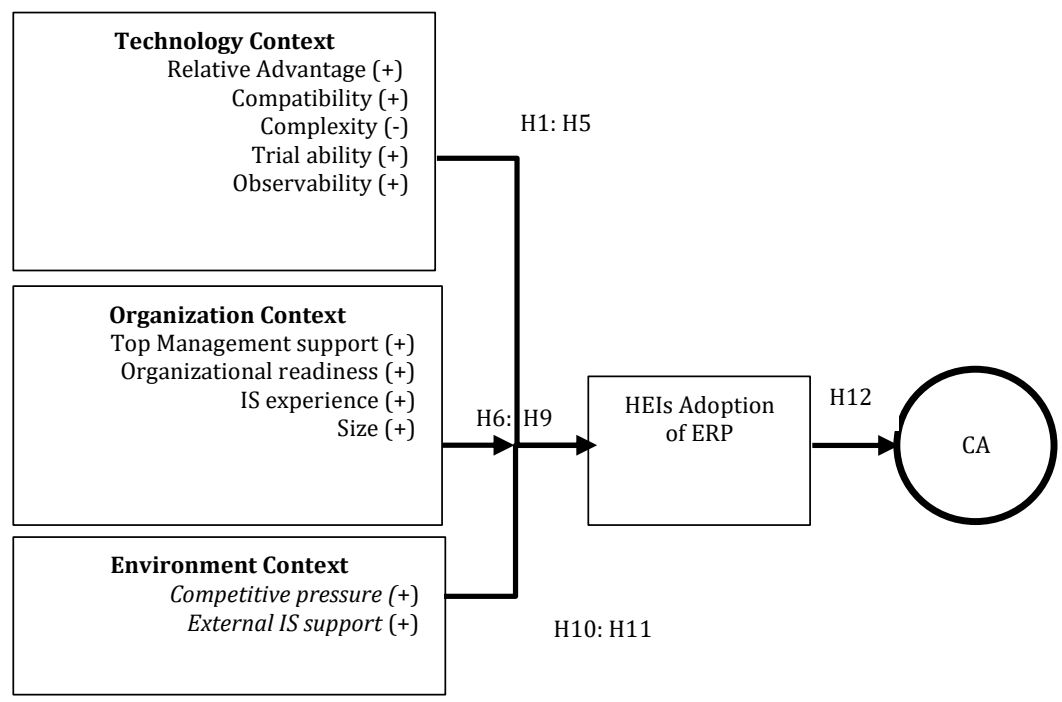

Fig. 1: Proposed research framework

H1. The greater the perceived relative advantage of ERP systems, the more likely they will be adopted by HEIs.

Compatibility of an innovation with a business is characterized as "the degree to which an innovation is perceived as consistent with the existing values, past experiences, and needs of potential adopters" (Rogers, 2003). Premkumar (2003) observed compatibility to be an imperative determinant of IS innovation adoption. The adoption of new technologies can convey critical changes to the work practices of businesses and resistance to change is an ordinary organizational reaction (Premkumar and Roberts, 1999). Thusly, it is imperative, particularly for HEIs, that the changes are compatible with its infrastructure, qualities and convictions.

H2. The greater the perceived compatibility of ERP systems with current infrastructure, qualities, and beliefs, the more likely they will be adopted by HEIs.

Complexity is characterized as "the degree to which an innovation is perceived as relatively difficult to understand and use" (Rogers, 2003). The complexity of the technology makes more noteworthy uncertainty for successful implementation and thusly expands the risk in the adoption decision (Premkumar and Roberts, 1999). This factor has been observed to be negatively related with the adoption of IS innovations (Grover, 1993). In addition, it has been found to be an important determinant of the adoption of IS innovations in some environments like the context of small business (Thong, 1999).

H3. The lower the perceived complexity of ERP systems, the more likely they will be adopted by HEIs.

"Trialability" is defined as "the degree to which an innovation may be experimented with on limited basis" (Rogers, 2003). This component has been observed to be positively identified with ecommerce adoption (Kendall et al., 2001). The IS innovations under examination in this study are presently new to the higher education market. Subsequently, trialability is expected to be outstandingly significant.

H4. HEIs with a greater ability to experiment with ERP systems before adoption are more likely to adopt them.

"Observability" is defined as "the degree to which the results of an innovation are visible to others" (Rogers, 2003). IS innovations that have been believed to have an effect in the higher education context will probably be seen in a positive light (Dwivedi et al., 2009). Henceforth, observability is expected to be exceptionally relevant to the higher education context.

H5. The more noteworthy the observability of ERP systems with regards to the context of higher education, the more probable they will be adopted.

\subsection{Organizational dimension}

This dimension focuses on how organization's characteristics and resources influence their decision to adopt technology innovation. Previous studies reported that organization dimension strongly influence on the organizational IT adoption of an innovation (Laukkanen et al., 2007). ERP system is an enterprise-wide generic solution, thus during implementation phase it requires vendors to customize the software according to HEIs' requirements. Hence, the well understanding of how HEIs' characteristics can be suitable for ERP system is very important in order to examine organization's decision to adopt new IT innovation.

Top management support can be characterized through a few features, incorporating leadership involvement with the project, leadership responsibility, and organization support company support. Past research has connected leadership commitment through managerial capacity to overcoming deterrents to the adoption of IT (Oliveira and Martins, 2011). In addition, Jeyaraj et al. (2006) observed top management support to be one of the best indicators of the organizational 
adoption of IS innovations. Top management can motivate change by communicating and supporting values through an explained vision for the organization (Schniederjans and Yadav, 2013). Many studies portrayed top management support to be as a basic factor for creating a supportive climate for the adoption of new technologies (Premkumar and Roberts, 1999). With regards to Higher Education context, the decision-maker is very probably going to be in the top management team and his/her support is a vital key for the IT adoption to occur.

H6. The greater the top management support for ERP systems, the more likely they will be adopted by HEIs.

Organizational readiness is defined as "the availability of the needed organizational resources for adoption". Organizational readiness, as discussed in past research on electronic data interchange (EDI) adoption, measures whether a firm has adequate IS sophistication and financial resources (Iacovou et al., 1995). In fact, monetary costs and shortage of technical experience are distinguished as two of the most critical components that hinder IS development within the organizations, especially small one (Cragg and King, 1993). IS complexity evaluates whether a firm is innovatively prepared to attempt the adoption of an IS innovation, while monetary assets express an organization's capital available to invest in an IS innovation (Chwelos et al., 2001).

H7. The greater the financial and technological resources, the more probable ERP system will be adopted by HEIs.

Firms that do not have much IS experience might be ignorant of new technologies or might not have any desire to take a risk to adopt them. Dholakia and Kshetri (2004) proposed that technologies effectively existing in an organization stimulus the future adoption of another new innovation. They contend that the incremental cost and knowledge required to adopt the internet, for instance, will be much slighter if a firm already owns a computer and a telephone. Likewise, other studies have found that earlier IS experience impacts the adoption of new technologies (Kuan and Chau, 2001).

H8. The more noteworthy the IS expertise available in the organization, the more probable ERP system will be adopted by HEIs.

Organizational size has been recognized by Jeyaraj et al. (2006) as one of the best organizational indicators of adoption of IS innovations. Goode and Stevens (2000) demonstrated that business size, previously the best indicator of technology adoption, was not significantly related to IS innovation adoption. Nevertheless, the typical argument is that bigger businesses have a noteworthy need, resources, skills and experience and the capability to survive failures than smaller businesses (Levenburg et al., 2006). Hence, it can be argued that larger firms are more probably to embrace ERP systems.

H9. The larger the size of the business, the more likely ERP systems will be adopted by HEIs.

\subsection{Environmental dimension}

HEIs decision to adopt ERP is not limited only to internal factors (organization and technology dimensions) but also influence by external factors. Tornatzky et al. (1990) explained that environmental dimension deals with industry segment, organization's competitors, and the regulatory environment. In this research, Competitive pressure and external IS support are described to be influences of HEIs' adoption of ERP systems.

Competitive pressure has been explained by Jeyaraj et al. (2006) as one of the best influential predictors of IT innovations adoption within the organization. Competition in general for the adopter's industry has a positive influence on the IT adoption of an innovative new technology (Gatignon and Robertson, 1989). Thus, this is argued to be even more evident if the innovation directly affects the competition (Kuan and Chau, 2001). Similarly, Premkumar and Ramamurthy (1995) concluded that it can be a strategic perspective to adopt new technologies to compete in the marketplace.

H10. The greater the competitive pressure, the more likely ERP systems will be adopted by HEIs.

External IS support refers to the availability of support for implementing and using IS innovations have been found to be positively influenced on IS innovation adoption (Premkumar and Roberts, 1999). DeLone (1988) claimed that External IS support to be an important determinant of IS success. With the popularity of outsourcing and the growth of third-party support, firms are more willing to adopt new IS innovations if they feel there is an adequate vendor or third-party support (Dwivedi et al., 2009).

H11. The greater the external IS support for ERP systems, the more likely they will be adopted by HEIs.

\section{Competitive advantage (CA)}

ERP system has become the determinant of competitive advantage for organizations around the world (Egdair et al., 2015). Other authors (Goeke and Faley, 2009; Karia et al., 2006; Ram et al., 2014) mentioned the following benefits that can eventually create competitive advantage: improved decisionmaking capabilities; improved inventory management; improved information and knowledge management (manifested through practices such as employee education and training); information networking; and knowledge sharing. Shang and Seddon (2002) proposed five dimensions of ERP benefits namely, operational, managerial, strategic, IT infrastructure and organizational. The same author, also, explained that ERP benefit was a continuous process with returns realized at a different rate in diverse core processes.

On the contrary, ERP systems may not provide a competitive advantage when adopted directly, despite the accuracy, easy access, and timing of the 
information provided by the faster processing of data (Johansson and Newman, 2010). Hence, there is a clear knowledge gap on how the adoption and implementation of ERP systems lead towards gaining the competitive advantage in the higher education sector that can thus motivate these institutions to adopt and implement ERP systems, especially in Egypt.

H12. ERP Adoption positively gives HEIs' Competitive Advantage (CA).

\section{Conclusion}

As a conclusion, this study is designed to understand the determinants of ERP adoption among HEIs in Egypt. This study contributes to the technology adoption, ERP and higher education literature review by 1) extending current understanding of ERP adoption within a Higher education context unlike earlier studies that examined ERP adoption among other contexts, 2) identifying factors of ERP adoption among HEIs to gain a competitive advantage, and 3) extending the use of TOE framework within ERP adoption among HEIs. This framework is proven to be relevant and consistent as a measurement scale for technology adoption. Hence, using this framework can provide a better understanding of what influence ERP adoption among HEIs in Egypt. Practically, this study contributes a guideline to HEIs to consider on adopting ERP systems based on TOE framework. Overall, this study is important as it can help HEIs to achieve competitive advantages through the adoption of ERP. With the current economic situation being able to systematically manage business operations are vital to sustaining competitive advantage.

\section{Acknowledgment}

This research is supported by USM fellowship from Institute of Postgraduate Studies (IPS) in Universiti Sains Malaysia (USM). The authors would like to thank the School of Management for providing these facilities for this research.

\section{References}

Abdelghaffar $\mathrm{H}$ and Azim RHA (2010). Significant factors influencing ERP implementation in large organizations: Evidence from Egypt. In the European, Mediterranean and Middle Eastern Conference on Information Systems (EMCIS), Abu Dhabi, UAE: 1-16.

Abdellatif HJ (2014). ERP in higher education: A deeper look on developing countries. In the International Conference on Education Technologies and Computers (ICETC), IEEE, Lodz, Poland: 73-78. https://doi.org/10.1109/ICETC.2014.6998905

Abugabah A and Sanzogni L (2010). Enterprise resource planning (ERP) system in higher education: A literature review and implications. International Journal of Human and Social Sciences, 5(6): 395-399.

Ajzen I (1991). The theory of planned behavior. Organizational Behavior and Human Decision Processes, 50(2): 179-211.
Al Kilani B, Adlouni S, Al Ahbabi S, and Al Yahyaei Z (2012). ERP Systems in Arab Education sector: Towards improved implementation. Information Systems Applications in the Arab Education Sector: 620-622. Available online at: https://pdfs.semanticscholar.org/c421/aabd54f0415a7ff520 b12912295ea66292d1.pdf

Albadri F (2012). Information systems applications in the Arab education Sector. Information Science Reference (IGI Global), Pennsylvania, USA.

ALdayel AI, Aldayel MS, and Al-Mudimigh AS (2011). The critical success factors of ERP implementation in higher education in Saudi Arabia: A case study. Journal of Information Technology and Economic Development, 2(2): 1-16.

Bernroider EW and Schmöllerl P (2013). A technological, organisational, and environmental analysis of decision making methodologies and satisfaction in the context of IT induced business transformations. European Journal of Operational Research, 224(1): 141-153.

Bradford M and Florin J (2003). Examining the role of innovation diffusion factors on the implementation success of enterprise resource planning systems. International Journal of Accounting Information Systems, 4(3): 205-225.

Chau PY and Tam KY (1997). Factors affecting the adoption of open systems: An exploratory study. MIS Quarterly, 21(1): 124.

Chwelos P, Benbasat I, and Dexter AS (2001). Research report: Empirical test of an EDI adoption model. Information Systems Research, 12(3): 304-321.

Cragg PB and King M (1993). Small-firm computing: Motivators and inhibitors. MIS Quarterly, 17(1): 47-60.

Davis FD (1986). A technology acceptance model for empirically testing new end-user information systems: Theory and results. Ph.D. dissertation, Massachusetts Institute of Technology, Cambridge, USA.

Davis FD (1989). Perceived usefulness, perceived ease of use, and user acceptance of information technology. MIS Quarterly, 13(3): 319-340.

Dedrick J and West J (2004). An exploratory study into open source platform adoption. In the the 37th Annual Hawaii International Conference on System Sciences, IEEE, Hawaii, USA: 1-11. https://doi.org/10.1109/HICSS.2004.1265633

DeLone WH (1988). Determinants of success for computer usage in small business. MIS Quarterly, 12(1): 51-61.

Dholakia RR and Kshetri N (2004). Factors impacting the adoption of the Internet among SMEs. Small Business Economics, 23(4): 311-322.

Dwivedi YK, Papazafeiropoulo A, Ramdani B, Kawalek P, and Lorenzo $O$ (2009). Predicting SMEs' adoption of enterprise systems. Journal of Enterprise Information Management, 22(1/2): 10-24.

Egdair IM, Rajemi MF, and Nadarajan S (2015). Technology factors, ERP system and organization performance in developing countries. International Journal of Supply Chain Management, 4(4): 82-89.

El Sawah S, Abd El Fattah TA, and Hassan RM (2008). A quantitative model to predict the Egyptian ERP implementation success index. Business Process Management Journal, 14(3): 288-306.

El Sayed M, Hubbard NJ, and Tipi NS (2013). Evaluating enterprise resource planning (ERP) post implementation problems in Egypt: Findings from case studies of governmental, multinational and private Egyptian organisations. University of Huddersfield Repository, Huddersfield, UK: 1-9. Available online at: http://eprints.hud.ac.uk/19207/1/HubbardEvalL RN_Paper_-_ElSayed_Hubbard__Tipi.pdf

Elragal AA and Al-Serafi AM (2011). The effect of ERP system implementation on business performance: An exploratory 
case-study. Communications of the IBIMA, 670212: 1-19. https://doi.org/ 10.5171/2011.670212

El-Seoud S, Taj-Eddin I, Seddiek N, Ghenghesh P, and El-Khouly M (2014). The impact of e-learning on Egyptian higher education and its effect on learner's motivation: A case study. Computer Science and Information Technology, 2(3): 179-187.

Gatignon H and Robertson TS (1989). Technology diffusion: an empirical test of competitive effects. The Journal of Marketing, 53(1): 35-49.

Ghuman K and Chaudhary S (2012). Incorporation of ERP in educational institutions: an empirical study. In the International Conference on Technology and Business Management: 318-324.

Goeke RJ and Faley RH (2009). Technical opinion Do SAP successes outperform themselves and their competitors?. Communications of the ACM, 52(10): 113-117.

Goode S and Stevens K (2000). An analysis of the business characteristics of adopters and non-adopters of World Wide Web technology. Information Technology and Management, 1(1): 129-154.

Grandon EE and Pearson JM (2004). Electronic commerce adoption: An empirical study of small and medium US businesses. Information and Management, 42(1): 197-216.

Grover V (1993). An empirically derived model for the adoption of customer-based interorganizational systems. Decision Sciences, 24(3): 603-640.

Haddara M and Elragal A (2013). ERP adoption cost factors identification and classification: A study in SMEs. International Journal of Information Systems and Project Management, 1(2): 5-21.

Hsu PF, Kraemer KL, and Dunkle D (2006). Determinants of ebusiness use in US firms. International Journal of Electronic Commerce, 10(4): 9-45.

Iacovou CL, Benbasat I, and Dexter AS (1995). Electronic data interchange and small organizations: Adoption and impact of technology. MIS Quarterly, 19(4): 465-485.

Ifinedo P (2011). An empirical analysis of factors influencing Internet/e-business technologies adoption by SMEs in Canada. International Journal of Information Technology and Decision Making, 10(04): 731-766.

Jeyaraj A, Rottman JW, and Lacity MC (2006). A review of the predictors, linkages, and biases in IT innovation adoption research. Journal of Information Technology, 21(1): 1-23.

Johansson B and Newman M (2010). Competitive advantage in the ERP system's value-chain and its influence on future development. Enterprise Information Systems, 4(1): 79-93.

Karia N and Hasmi Abu Hassan AM (2006). The effects of total quality management practices on employees' work-related attitudes. The TQM Magazine, 18(1): 30-43.

Kendall JD, Tung LL, Chua KH, Ng CHD, and Tan SM (2001). Receptivity of Singapore's SMEs to electronic commerce adoption. The Journal of Strategic Information Systems, 10(3): 223-242.

Kuan KK and Chau PY (2001). A perception-based model for EDI adoption in small businesses using a technologyorganization-environment framework. Information and Management, 38(8): 507-521.

Laukkanen S, Sarpola S, and Hallikainen P (2007). Enterprise size matters: Objectives and constraints of ERP adoption. Journal of Enterprise Information Management, 20(3): 319-334.

Lee J (2004). Discriminant analysis of technology adoption behavior: A case of Internet technologies in small businesses. Journal of Computer Information Systems, 44(4): 57-66.

Lee OKD, Wang MW, Lim KH, and Peng ZJ (2009). Knowledge management systems diffusion in Chinese enterprises: A multistage approach using the technology-organization- environment framework. Journal of Global Information Management, 17(1): 1370-1371.

Levenburg N, Magal SR, and Kosalge P (2006). An exploratory investigation of organizational factors and e-business motivations among SMFOEs in the US. Electronic Markets, 16(1): 70-84.

Liaquat H, Jon DP, and Rashid A (2002). Enterprise resource planning: Global opportunities and challenges. Idea Group Publishing, London, UK.

Lotfy MAMB (2015). Sustainability of enterprise resource planning (ERP) benefits postimplementation: An individual user perspective. Ph.D. Dissertations, Walden University, Minnesota, USA.

Lyytinen K and Damsgaard J (2011). Inter-organizational information systems adoption- A configuration analysis approach. European Journal of Information Systems, 20(5): 496-509.

Markus ML and Tanis C (2000). The enterprise systems experience-from adoption to success. Framing the Domains of IT Research: Glimpsing the Future through the Past, 173: 207173.

Marques A, Oliveira T, Dias SS, and Martins MFO (2011). Medical records system adoption in European hospitals. Electronic Journal of Information Systems Evaluation, 14(1): 89-99.

McCredie J and Updegrove D (1999). Enterprise system implementations: Lessons from the trenches. Cause/Effect, 22(4): 9-16.

Mora-Monge CA, Azadegan A, and Teich J (2010). Effective benchmarking of innovation adoptions: A theoretical framework for e-procurement technologies. Benchmarking: An International Journal, 17(4): 472-490.

Oliveira T and Martins MF (2010). Firms patterns of e-business adoption: Evidence for the European Union-27. The Electronic Journal Information Systems Evaluation, 13(1): 47-56.

Oliveira $\mathrm{T}$ and Martins MF (2011). Literature review of information technology adoption models at firm level. The Electronic Journal Information Systems Evaluation, 14(1): 110-121.

Oliveira T, Thomas M, and Espadanal M (2014). Assessing the determinants of cloud computing adoption: An analysis of the manufacturing and services sectors. Information and Management, 51(5): 497-510.

Pan MJ and Jang WY (2008). Determinants of the adoption of enterprise resource planning within the technologyorganization-environment framework: Taiwan's communications industry. Journal of Computer Information Systems, 48(3): 94-102.

Pollock N and Cornford J (2004). ERP systems and the university as a "unique" organisation. Information Technology and People, 17(1): 31-52.

Premkumar G (2003). A meta-analysis of research on information technology implementation in small business. Journal of Organizational Computing and Electronic Commerce, 13(2): 91-121.

Premkumar G and Ramamurthy K (1995). The role of interorganizational and organizational factors on the decision mode for adoption of interorganizational systems. Decision Sciences, 26(3): 303-336.

Premkumar G and Roberts M (1999). Adoption of new information technologies in rural small businesses. Omega, 27(4): 467-484.

Qian LY, Baharudin AS, and Kanaan-Jebna A (2016). Factors affecting the adoption of enterprise resource planning (ERP) on cloud among small and medium enterprises (SMES) in Penang, Malaysia. Journal of Theoretical and Applied Information Technology, 88(3): 398-409. 
Ram J, Wu ML, and Tagg R (2014). Competitive advantage from ERP projects: Examining the role of key implementation drivers. International Journal of Project Management, 32(4): 663-675.

Rogers EM (2003). Diffusion of Innovations. Free Press, New York, USA.

Ruivo P, Oliveira T, and Neto M (2014). Examine ERP postimplementation stages of use and value: Empirical evidence from Portuguese SMEs. International Journal of Accounting Information Systems, 15(2): 166-184.

Schniederjans D and Yadav S (2013). Successful ERP implementation: An integrative model. Business Process Management Journal, 19(2): 364-398.

Seo G (2013). Challenges in implementing enterprise resource planning (ERP) system in large organizations: Similarities and differences between corporate and university environment. Ph.D. dissertation, Massachusetts Institute of Technology, Cambridge, USA.

Shah Alam S (2009). Adoption of internet in Malaysian SMEs. Journal of Small Business and Enterprise Development, 16(2): 240-255.

Shang S and Seddon PB (2002). Assessing and managing the benefits of enterprise systems: the business manager's perspective. Information Systems Journal, 12(4): 271-299.

Soliman M and Karia N (2015a). Enterprise resource planning systems in higher education context: Functionalities and characteristics. International Journal of Innovative Research in Science, Engineering and Technology, 4(11): 10408-10413.

Soliman M and Karia N (2015b). Higher education competitive advantage: Enterprise resource planning systems. International Journal of Research in Management and Technology (IJRMT), 5(5): 380-384.

Thong JY (1999). An integrated model of information systems adoption in small businesses. Journal of Management Information Systems, 15(4): 187-214.
Tornatzky LG, Fleischer M, and Chakrabarti AK (1990). The processes of technological innovation. Lexington Books, Maryland, USA.

Venkatesh V, Morris MG, Davis GB, and Davis FD (2003). User acceptance of information technology: Toward a unified view. MIS Quarterly, 27(3): 425-478.

Wang YM, Wang YS, and Yang YF (2010). Understanding the determinants of RFID adoption in the manufacturing industry. Technological Forecasting and Social Change, 77(5): 803-815.

Watson EE and Schneider H (1999). Using ERP systems in education. Communications of the AIS, 1(9): 1-48.

Wu Y, Cegielski CG, Hazen BT, and Hall DJ (2013). Cloud computing in support of supply chain information system infrastructure: Understanding when to go to the cloud. Journal of Supply Chain Management, 49(3): 25-41.

Zhu K and Kraemer KL (2005). Post-adoption variations in usage and value of e-business by organizations: Cross-country evidence from the retail industry. Information Systems Research, 16(1): 61-84.

Zhu K, Dong S, Xu SX, and Kraemer KL (2006). Innovation diffusion in global contexts: determinants of post-adoption digital transformation of European companies. European Journal of Information Systems, 15(6): 601-616.

Zhu K, Kraemer K, and Xu S (2003). Electronic business adoption by European firms: a cross-country assessment of the facilitators and inhibitors. European Journal of Information Systems, 12(4): 251-268.

Zhu K, Kraemer KL, and Dedrick J (2004). Information technology payoff in e-business environments: An international perspective on value creation of e-business in the financial services industry. Journal of Management Information Systems, 21(1): 17-54 